\title{
Research on mathematics teachers as partners in task design
}

\author{
Keith Jones $^{1} \cdot$ Birgit Pepin ${ }^{2}$
}

Published online: 8 March 2016

(C) Springer Science+Business Media Dordrecht 2016

\begin{abstract}
Mathematical tasks and tools, including tasks in the form of digital tools, are key resources in mathematics teaching and in mathematics teacher education. Even so, the 'design' of mathematical tasks is perceived in different ways: sometimes seen as something distinct from the teaching and learning process, and sometimes as integral to it. Whilst task design has often been carried out by designers or mathematicians (perhaps as textbook authors), the focus for this review article is research that has involved mathematics teachers as partners in the design of tasks. The article provides a state-of-the-art review of relevant literature and is presented under three headings that consider, in turn, the role of mathematical 'tasks'; the nature of 'task design'; and the notion of 'partnerships for task design' in mathematics education. Subsequently, we present current research that is providing new insights into tasks, task design, and task design partnership. Based on this, we argue that 'task design' needs to pay particular attention to what to design, which tools are necessary or beneficial, and under what conditions; digital tools and task resources offer particular affordances that traditional resources cannot provide; and not only do teachers benefit from being partners in task design (in terms of their professional learning) but without their involvement some aspects of task design would most likely be neglected.
\end{abstract}

Keywords Mathematics education - Teachers - Partners - Partnership - Task design

Keith Jones

d.k.jones@soton.ac.uk

$\square$ Birgit Pepin

b.e.u.pepin@tue.nl

1 Southampton School of Education, University of Southampton, Southampton SO17 1BJ, UK

2 Eindhoven School of Education, Technische Universiteit Eindhoven, P.O. Box 513, Eindhoven 5600 MB, The Netherlands 


\section{Introduction}

Mathematics teachers work with mathematical task all the time, in their daily preparation work and during classroom instruction. Moreover, in their lesson preparation, they choose, modify, and sometimes design tasks, for example, for their students to undertake a mathematical activity or practice exercise. At the same time, as affirmed by Henningsen and Stein (1997, p. 525), students '...develop their sense of what it means to 'do mathematics' from their actual experiences with mathematics, and their primary opportunities to experience mathematics as a discipline are seated in the classroom activities in which they engage...'.

Hence, the kinds of tasks that teachers ask students to do in mathematics lessons portray 'mathematics' as a subject to students. Numerous studies have investigated mathematical tasks and the use of tasks by teachers, and many have highlighted how tasks provide 'opportunities to learn' for students. Indeed, research has documented how teachers' decisions about the selection of tasks are often directly related to their perceptions of teaching and learning, and that tasks (e.g. in textbooks) are often regarded as influencing, and sometimes determining, the degree of students' opportunities to learn (e.g. Haggarty and Pepin 2002; Schmidt et al. 1997; Törnroos 2005). As such, Sullivan and Mousley (2001), for example, have argued that teacher professional development should focus on supporting teachers in understanding the complexity of decision-making about classroom tasks (this idea being taken up by Clarke et al. 2009 and Zaslavsky and Sullivan 2011, and by several chapters in Tirosh and Wood 2008).

Teachers' work with mathematical tasks is not restricted to the use of tasks in, and for, instruction, and teachers do not necessarily work on their own. Indeed, the ways teachers work with tasks (amongst other resources) have been investigated and theorised in different ways. For example, echoing selected aspects of Remillard's (2005) work, Pepin et al. (2013) see teachers' work with resources such as tasks as a firmly interactive process between the teacher and the resource/s. Pepin et al. (p. 1) write:

Resources are essential for mathematics teachers, and teachers use different kinds of resources, which shape the mathematical content presented to, and used by, pupils in their [mathematics] learning. Moreover, when appropriating resources, teachers adapt them to their needs and customs. This process of 'design' and interpretation of resources then continues 'in use' - hence transformation is seen here as 'design-inuse'. (Pepin et al. 2013, p. 1)

It is recognised that when teachers interact with curriculum resources (such as mathematical tasks), they develop knowledge-individually when preparing their lessons and collectively in professional development sessions and other interactions with their colleagues. When working with mathematical tasks, adapting and appropriating them, teachers enhance their mathematical knowledge and their mathematics-didactical design capacity (Pepin 2015).

As already noted, teachers' interaction with different resources, such as tasks, has been theorised in various ways (e.g. Gueudet and Trouche 2009; Pepin et al. 2013; Remillard 2005). What is clear from these theoretical frames is that such interaction is a participatory two-way process in which teachers are influenced by the resources and the design of resources is influenced by the teachers. Making sense of, and using, classroom resources to design and enact instruction places a demand on a specific teacher capacity, that of teachers' pedagogical design capacity - the capacity to utilise existing curricular resources 
effectively to design instruction (Brown 2009). At the same time, a teacher's pedagogical design capacity is dependent, at least to some extent, on the particular resource being used (given that each resource has different affordances and constraints), and on the ways of working, individually or collectively, with the resource.

The collective dimension is an important aspect of teachers' professional development and design capacity building (Gueudet et al. 2013). The literature on 'communities of practice' (Wenger 1998) and literature on 'communities of inquiry' (Jaworski 2006) are but two examples that provide evidence of the delicate interrelationships between teachers, mathematical tasks, and teachers working in collectives. To try to develop deeper insights into processes and relationships involved in 'teachers as partners in tasks design', entails developing deeper understandings of the role of 'tasks' (as compared, for example, to other resources); of 'teachers as partners' (as compared, for example, to teachers as followers of particular schemes); and of 'task design' (as compared to teachers as 'implementers' of pre-designed curriculum resources).

Here, we note that 'task design' refers to mathematical tasks (including tasks in the form of digital resources and tools) that are developed and designed in, or for, mathematics teaching, or in, or for, mathematics teacher education. Hence, task design could include designing tasks for teaching specific mathematical topics to specific learners, designing tasks for textbooks (including digital platforms and e-books), designing learning sequences, and designing tasks for the professional learning of mathematics teachers. From a review of studies that have examined classroom tasks, de Araujo and Singletary (2011, p. 1207) concluded that 'teachers' perspectives on tasks were lacking'. Alongside Schoenfeld's (2009) call for greater communication between educational designers and researchers, Geiger et al. (2014, p. 240) note that 'partnerships between teachers and researchers, where understandings of principles of task design and the effective integration of tasks with pedagogical approaches are explored, refined and documented, holds potential for improving teaching and learning practices in mathematics'.

In what follows, we review the range of research that has involved teachers as partners in task design. The article is divided into five further parts: first, we outline the role of mathematical tasks in the teaching and learning of mathematics; second, we show ways of considering the design of tasks; and third, we review research on partnerships for task design in mathematics education. In the fourth section, we present current research that is pointing towards new insights into tasks, task design, and partnership for task design. In the fifth and final part, we summarise our insights and conclusions.

\section{The nature and role of mathematical 'tasks' in mathematics education}

The relationship between the types of tasks students engage in when learning mathematics and the mathematics they learn has been, as Arbaugh and Brown (2005, p. 503) explain, a subject of research 'for many years'. Similarly, Krainer (1993, p. 65) notes that 'discussing the importance of tasks in mathematics education has a long tradition'. The reason for this focus on the nature and role of mathematical tasks in mathematics education is because, as Doyle (1983, p. 161) said, tasks 'influence learners by directing their attention to particular aspects of content and by specifying ways of processing information' and, as Stein et al. (1996, p. 459) observed, tasks determine 'not only what substance [students] learn but also how they come to think about, develop, use, and make sense of mathematics'. Such conclusions were echoed more recently by Sullivan et al. (2012, p. 14) in their premise for 
mathematics teaching that "mathematical thinking comes from students working on a succession of problem-like tasks, rather than following the teacher's instructions step-bystep'.

Various ways have been used to classify, or typify, the nature of mathematical tasks designed for, and used in, mathematics classrooms around the world. Shimizu et al. (2010, p. 3), for example, identified task categories such as 'authentic', 'rich' and 'complex' and point to issues with such categorisation (for example, whether 'authentic' implies an 'inauthentic' category). Other categorisations in use include 'open'/'closed' tasks and 'worthwhile' tasks. Sullivan et al. (2012, p. 24) argue for what they call 'purposeful representational tasks', ones that they view as 'conceptually focused' and which 'purposefully make use of models, representations, or other tools'. A framework of five types of task has been devised by Swan $(2005,2011)$. The five types are as follows: classifying mathematical objects (entailing students devising or applying a classification); interpreting multiple representations (where students draw links between representations); evaluating mathematical statements (where students decide on the validity of mathematical statements); creating problems for others to solve (where students create problems for their class); and analysing reasoning and solutions (where students identify errors and compare solutions).

In terms of the role of tasks, a useful distinction between task and activity was proposed by Christiansen and Walther (1986). Here, a 'task' is what the learner is asked to do, whilst the 'activity' of working on the task (including interaction with other learners, other resources, and the teacher) influences the learning that results. Going further, Stein et al. (1996) proposed that the nature and role of mathematical tasks in the classroom might be conceptualised from three viewpoints: mathematical tasks as presented in instructional materials; mathematical tasks as set up by a teacher in their classroom (which may be adaptation of tasks as presented in instructional materials); and mathematical task as implemented by students (which may entail interpretation of tasks, either when presented in instructional materials or when set up by the teacher).

With these varying ways of classifying and conceptualised tasks, in the next section we outline ways that task design has been considered within research in mathematics education.

\section{Task 'design' in mathematics education}

Typically, task 'design' is considered as entailing curriculum developers (such as textbook writers) devising mathematical tasks which subsequently get 'implemented' by teachers in their classroom instruction. In contrast, in a recent ZDM issue (volume 45, issue 7), Pepin et al. (2013) argue that different processes are at stake in teachers' work with curriculum resources such as tasks. They explain that teachers' interaction with tasks might involve one or a more of the following:

1. In choosing tasks, the processes involved are likely to be 'adoption' (of, say, textbook tasks; see for example, Ball and Cohen 1996) and/or 'integration' of the curriculum materials/tasks (in the case of, say, digital technologies; see for example, Ruthven and Hennessy 2002);

2. Given teacher-task interaction is a two-way process, the process is one of resource 'genesis', or 'appropriation' (Gueudet et al. 2012; Remillard et al. 2008); see below for more on the process of resource 'genesis'; 
3. With the transformative potential of the teacher-task relationship, there are 'educative' curriculum materials (Davis and Krajcik 2005) that are intended to promote teacher learning (for example, materials which help teachers to develop pedagogical design capacity; see Brown 2009).

The third of these processes is arguably one of the most important learning processes, where the teachers develop their design capacity and, in turn, their agency by working with mathematical curriculum materials/tasks. This full set of processes points to viewing teachers as partners in task/resource design as an interactive process. The processes also imply that a teacher's pedagogical design capacity is going to be influenced by the particular curriculum tasks/resources (and their educative features).

Pepin et al. (2013) note that there have been a number of proposals to define 'design research' in mathematics education (e.g. Wittmann 1995, 2001) and point to the work of the Freudenthal Institute in the Netherlands (e.g. Gravemeijer 1993; Gravemeijer and Cobb 2006); work in the USA (e.g. 'teaching experiment methodology', Cobb and Steffe 1983); and the European traditions of didactical research, in particular didactical engineering (Artigue 1994; Brousseau 1997). Didactical design, in Ruthven et al.'s (2009, p. 329) words, is 'the design of learning environments and teaching sequences informed by close analysis of the specific topic of concern and its framing within a particular subject area'. Recent studies that have employed a didactical design approach include Ruthven and Hofmann (2013) who report on the design of a probability module intended for implementation at scale in early secondary education in England, and Sensevy (2012) who develops the notion of collaborative didactical engineering where primary school teachers, teacher educators, and researchers work together on didactical designs. Moreover, a recent special issue of ZDM, the International Journal on Mathematics Education (see Prediger et al. 2015), was devoted to design research, with a particular focus on learning processes.

As noted above, designing tasks for the professional learning of mathematics teachers is another genre of work (and research) on mathematical task design. For example, in the introduction to the Journal of Mathematics Teacher Education (JMTE) triple special issue (volume 10, issues 4-6; edited by Zaslavsky, Watson and Mason) focussing on the Nature and Role of Tasks in Mathematics Teachers' Education, Watson and Mason (2007, pp. 207-208) note that the pre-service and in-service education of mathematics teachers can include prompting them to 'engage in mathematical thinking through working on mathematics-related tasks..., reflect on the experience of doing mathematics-related task..., consider implications for teaching...'. This reflecting and considering might include 'designing and trying out related mathematics-related tasks with learners, as well as extending and varying task structure and task presentation' (ibid).

Having considered task 'design', we turn to surveying recent research on partnerships for task design in mathematics education.

\section{On 'partnerships for task design' in mathematics education}

In the Discussion Document for the recent ICMI Study on Task Design in Mathematics Education, Watson and Ohtani (2014, p. 11) observe that whilst task design and teaching can be seen as 'separate acts carried out by separate groups of people', the communities involved in task design 'are naturally overlapping and diverse' such that 'design can involve designers, professional mathematicians, teacher educators, teachers, researchers, learners, authors, publishers and manufacturers, or combinations of these' (ibid). This 
raises the issue of what is known from research that has involved mathematics teachers as partners in task design. At the ICMI Study 22 conference (see Margolinas 2014, for the proceedings), only a modicum of contributions especially addressed this issue. Perhaps as a consequence, relatively modest attention is paid to the issue in the book resulting from the ICMI study (see Watson and Ohtani 2015a). Given this, it is appropriate that a focus of this article, and this Special Issue of JMTE, is the research that, to date, has involved mathematics teachers as partners in the design of tasks for the teaching and learning of mathematics.

Various research and development teams have, over the years, undertaken collaborative efforts aimed at developing and testing task designs for improving the teaching and learning of mathematics. The term 'partnership', as Coburn et al. (2013, p. 2) explain, can refer to many different arrangements such as 'consulting relationships', 'university-school partnerships', and 'research projects'. More specific terms also currently in use include 'research-practice partnerships', defined by Coburn et al. (ibid) as 'long-term, mutualistic collaborations between practitioners and researchers that are intentionally organised to investigate problems of practice and solutions for improving district outcomes', and 'design-based implementation research', defined by Penuel et al. (2011, p. 311) as an approach focusing on 'persistent problems of practice from multiple stakeholders' perspectives' whilst having a commitment to 'iterative, collaborative design' and a concern with 'developing theory related to both classroom learning and implementation through systematic inquiry' and 'developing capacity for sustaining change in systems'.

As well as such forms of partnership, notions such as 'mathematics education as a design science' (Wittmann 1995), 'teaching as design' (Brown and Edelson 2003), and the 'teacher as designer' (Maher 1987) have gained attention-sometimes as a form of professional development such as 'teacher design research' (Bannan-Ritland 2008). Applying the design metaphor to teaching is useful, Brown $(2009$, p. 23) explains, because it 'calls attention to the constructive interplay that takes place during instruction between agent (teachers) and tools (curriculum materials)'.

Given this history of collaborative efforts aimed at developing and testing designs for improving teaching and learning, as well as the notion of teaching as design and teacher as designer, there are several ways to conceptualise collaborative partnerships. These ways include considering a partnership as a form of 'co-learning agreement' (CLA) (Wagner 1997 ) or as a form of 'community of practice' (CoP) (Lave and Wenger 1991; Wenger 1998) or 'community of interest' (CoI) (Fischer 2001) — where, typically, the 'community' in a CoP can be thought of as homogeneous, whilst in a CoI the 'community' is heterogeneous. Sometimes such conceptualisations are viewed within the frame of Activity Theory (Engeström 1999, 2014).

Here, we briefly consider CLA, CoP, and $\mathrm{CoI}$ in turn. The idea of a co-learning agreement (CLA) was suggested by Wagner (1997) as a way of integrating practitioners into the research process so that research involved joint planning, joint implementation, and joint evaluation. Jaworski (2001, p. 316) developed this in mathematics education with the idea of the 'co-learning partnership model of teaching development' (see, also, Jaworski 2003). Subsequently, Jaworski suggested that as part of this co-learning inquiry model of teaching development, teachers could 'explore the design and implementation of tasks, problems and activity in classrooms' (Jaworski 2006, p. 203). Edwards and Jones (2003) provide an example report of a co-learning agreement in practice, whilst Jaworski et al. (2011) document the 'life cycle' of a task within a colearning community. 
Lave and Wenger's (1991, p. 98) idea of a 'community of practice' (CoP) entails 'participation in an activity system about which participants share understandings concerning what they are doing and what that means for their lives and for their communities'. Wenger (1998, p. 73) built on this by arguing that a CoP has three aspects: '(1) mutual engagement; (2) a joint enterprise; (3) a shared repertoire'. As an example of the CoP idea in mathematics education, Cobb et al. (2009, p. 187) have shown how they 'engaged the teachers in activities in which they used a common instructional task with their students and then analyzed the resulting student work in the subsequent professional development session'. Fischer (2001, p. 4) proposed the idea of 'Communities of Interest' (CoIs) as the bringing together of 'stakeholders from different CoPs to solve a particular (design) problem of common concern'. As such, a CoI is a variation on a CoP rather than being something very different. In mathematics education research, Bokhove et al. (2014, p. 171) say that the $\mathrm{CoI}$ in their project 'functions as a springboard for new resources to be used and developed to facilitate exchange, integration and thus creative thinking and working'.

More recently, Gueudet and Trouche $(2012 a, b)$ have extended their idea of what they have termed teachers' 'documentation' work-which includes 'looking for resources, selecting/designing mathematical tasks, planning their succession and the associated time management, etc.' (Gueudet and Trouche 2009, p. 201). In their extension, they paraphrase Lave and Wenger by proposing that 'each teachers' community of practice is a community of documentation' and that this means that 'community geneses and documentation geneses act in concert' such that the 'documentation work leads to the production of temporary objects as 'lived' resources, always engaged in new evolutions' (Gueudet and Trouche 2012b, p. 320).

In a follow-up study, Gueudet et al. (2013, p. 1013) argue that 'the conditions for the development of teachers' collective documentation work are likely to correspond to the conditions of the emergence of teachers' CoPs'; indeed, they contend that teachers working together (such as in the same school) do not necessarily build a CoP. In their view, there are certain conditions for the development of a CoP: for example, that the work with tasks and resources in collectives needs a shared purpose; that every emerging CoP needs a 'minder' of the collaborative task design work; and that there needs to be 'common forms of addressing and making sense of resources' (i.e. individual tasks turn into collective ones 'when teachers made sense of them and used them collectively for planning for and in instruction', ibid, p. 1014). This means that, by this argument, for teachers to become partners, it is essential that they work on common resources and share professional knowledge and beliefs about the teaching of mathematics. As has been established by research on the 'documentation' processes, this is a twofold process.

A number of existing studies have reported positively on involving teachers as partners in task design. Askew and Canty (2013), for example, in focusing on collaborative research developed between the staff of a primary school and a university researcher/task developer, examined how teachers worked with, and developed, classroom tasks as springboards for developing students' reasoning in mathematics. They concluded that the introduction of a framework for working on, and with the tasks, and treating this as a joint endeavour, promoted teacher inquiry and collegiality. Knott et al. (2013) examined the features of task design to which teachers needed to attend when modifying their existing lessons in order to engage students in learning new forms of generalisation and justification. They found that their way of working supported teachers who could then independently create rich tasks that moved their students towards justifying and generalising. Moss et al. (2015) adapted 
Japanese lesson study with teachers and researchers co-designing and carrying out exploratory lessons. They found that this approach was successful in supporting the teachers in gaining deeper content knowledge and in broadening their conceptualisation of geometric and spatial reasoning. In conducting classroom design research with teachers, Stephan (2015) concluded that the teachers with which she worked rated collaborative 'lesson imaging' as the most important activity in which they engaged during the project. Here, 'lesson imaging' entails using a recap of the mathematical ideas that emerged in their classes on a particular, day to help inform new classroom tasks. This, the teachers felt, was different to lesson planning, where that is the act of scheduling the tasks to be done in a lesson.

In investigating the conditions under which teacher 'communities of practice' develop in schools, Gueudet et al. (2013) found that the collective preparation of lessons, or tasks, was a central aspect. In line with this, Ron et al. (2013) argue that their study established the need to work with teachers in ways that develop and expand their pedagogical toolbox and encourage them to build on it when they design and make choices regarding specific tasks for certain purposes. In the case of digital technologies, Fuglestad et al. (2010) argue that by increasing the sense of ownership that teachers feel for the tools and tasks to be implemented, perhaps it also becomes more natural for them to accept the challenges of becoming active agents in the process of creating new cultures of practices which capitalise on the possibilities of digital tools.

Notwithstanding these positive findings, researchers have posited a range of cautions. Visnovska et al. (2012, p. 339), for example, caution that 'the common assumption that groups of teachers are capable of designing coherent instructional sequences from provided materials with little if any ongoing support is a dangerous misinterpretation of both the potential of teacher collaboration and the fact that implementation is necessarily an act of design'. Similarly, Goodchild (2014, p. 315) concludes that 'perhaps expecting teachers to engage in the design process from first principles is too ambitious'. Here, he notes, more attention may need to be given to initiating development from shared experiences that have been gained within the same constitutional, institutional, temporal, and social constraints that teachers recognise in their own practice. In their project on task design within a school-based professional development programme, Ding et al. (2013) point to the role that an 'expert teacher' (a 'knowledgeable other' with a range of expertise; see Yang 2014) can play in supporting teachers to develop their knowledge and ideas during school-based task design and implementation.

More specifically, Sensevy et al. (2013) conclude that what they term 'cooperative engineering' between teachers and researchers to design tasks involves both long task sequences and a sufficient duration of time, perhaps stretching to several years. In studying teachers as participants in textbook task development, Even and Olsher (2014) report that most of the teachers with which they worked could accept the role of preparing a textbook rather easily, often by using the knowledge that they had acquired from their own teaching experience as a springboard. In contrast, some of the teachers were wary of making changes to a textbook written by expert curriculum developers out of respect for the expertise of the textbook authors. In their task design project, Maßß et al. (2013) found a tension (sometimes even a contradiction) between curricular intentions (and societal demands) on the one hand, and current school organisation (and teaching practices) on the other. They argue that teachers can play a crucial role in the reduction in such tensions. Barbosa and de Oliveira (2013) identified a range of conflicts in their experience of a 
collaborative group that designed tasks for other teachers. They categorised the conflicts in terms of context, use of language, structure, distribution, and subjects. In working with teachers, Liljedahl (2015) reports that what he calls 'catalysing experiences' were effective only when they occurred within a context that was largely unfamiliar to the teachers. It was this that helped drive the teachers to make significant changes within their mathematics teaching.

\section{Recent research on tasks, design, and partnership in mathematics education}

This section introduces the different contributions to this double special issue of JMTE and draws together selected ideas on, and issues concerning, mathematics teachers as partners in task design. Overall, it is clear that all nine contributions include collaborative activities, albeit amongst different groups of participants (e.g. teachers-researchers; teachers-students; and teachers-designers-researchers). Further analysis has enabled us to group the nine articles under three themes, with each theme containing three articles. The three themes we identified are (1) collective mathematical task design; (2) co-designing and use of digital tools; and (3) particular collective design. In the "Appendix" to this article, we provide a table of all nine articles, drawing out their particular contributions.

Group (1) contains the articles by Coles and Brown (2015), Thanheiser et al. (2015), and Johnson et al. (2015). Whilst all three articles discuss mathematical task design in collectives (albeit different ones), each author team uses a different tool/theme for their argumentation, and consequently each points to different results and recommendations. Thanheiser et al. (2015) emphasise the value of 'reflective analysis' of the task implementation as an essential tool for going beyond designing and implementing, and they provide evidence for the importance and vitality of the reflective analysis phase. In addition, they recommend that (a) considering results from multiple (albeit related) tasks might be more beneficial than individual task analysis, and (b) the nature of tasks (e.g. problem-solving vs. problem-posing) should vary in order to help illuminate teachers' developing understandings. Coles and Brown (2015), working in a teacher-researcher partnership, recommend particular design principles (devised around 'the making of distinctions') and an explicit language of mathematical thinking in task design, in order to address the 'tension/s' between teacher intentions and student activity. 'Tensions' are also the theme of the article by Johnson et al. (2015). These can be tensions between designers and participants in terms of diverging goals in terms of implementing new standards. Such tensions can stem from a lack of design consensus and often become apparent when teachers engage in task analysis in professional development (sessions). However, rather than denying these tensions, this study argues that one of the promising approaches to the implementation of new standards is based a 'successful confrontation of project tensions in a collaborative design process'.

Group (2) articles include: Gueudet et al. (2015); Hansen et al. (2016); and Misfeldt and Zacho (2015). The three articles address the collective design of digital resources, where the co-design processes are supported by technology. In the study by Gueudet et al. (2015), the team investigated (at macro- and at micro-level) the design processes of a group of mathematics teachers (belonging to the Sesamath association) working with system pro- 
grammers, when they collaboratively worked on the co-design an e-textbook. This development did not advance 'linearly'; rather, it responded to particular tensions at different moments. During the project, it became evident that whilst technology could afford flexibility, teachers' perceptions of learning (and teaching) eventually determined the characteristics of the design. In the case of the article by Hansen et al. (2016), the team also explored the impact of co-designing a digital tool/virtual manipulative (namely Fractions $\mathrm{Lab}$ ), this time with a focus on the influence of co-designing on teachers' technological, pedagogical, and content knowledge. In terms of successful co-design of virtual manipulatives in communities of practice, their results pointed to (1) 'careful bootstrapping of the first design iteration' (in terms of content area and technological affordances/constraints, and (2) 'the involvement of highly motivated teachers' ready to become 'agents of change' in the domain. Interestingly, the third article in this group (by Misfeldt and Zacho 2015) studied 'how the design of educational scenarios can support teachers' adoption of technology and open-ended projects' aimed at endorsing creativity and innovation. Existing digital tools (Geogebra; Google sites) were used to develop digital learning environments. There was evidence that the notion of 'game' (playing a game) could support collaborative design and help teachers (in this study, primary school teachers) to engage with technology and open-ended projects.

In our last section, we have grouped the articles of Wake et al. (2015), Tempier (2015), and Jung and Brady (2015) because together they exemplify particular analytical approaches applied to studying teachers as partners in task design. The article by Wake et al. (2015) uses Lesson Study as an approach for professional learning (for teachers learning about processes of mathematical problem-solving). Here, the CHAT (culturalhistorical activity theory) frame was used to analyse and theorise from the data (as did Gueudet et al. 2015). In their analysis, Wake and colleagues identified two activity systems (classroom system and lesson study system) connected by a boundary object (the lesson plan). This is particularly helpful for illustrating 'how professional learning takes place through the introduction of carefully designed artefacts that draw on teachers' professional knowledge', not an entirely new idea, but particularly valuable for emphasising the experience and care needed for developing suitable design approaches. Interestingly, Wake and colleagues use the notions of instrumentation/instrumentalisation, a theoretical frame on which the Documentational Approach to Didactics (used by Gueudet et al. 2015) is based. Leaning on French notion of 'didactical engineering (for development)', Tempier (2015) highlights the affordances and constraints of a particular resource for the teaching and learning of the decimal system, and selected didactical phenomena related to the use of the resource by teachers. Moreover, he claims that in 'didactical engineering for development', the nature of the teacher/researcher partnership may vary according to the development issue at stake and the nature of the resource (and indeed several resources may be needed for particular issues). Jung and Brady (2015) use design-based research (DBR) as a means of working in partnership with teachers. They conclude that this way of working supports the development of shared objectives, and their study supports 'the value and viability of ... in situ professional development'. Interestingly, DBR is seen as one of the main ways to support, and research, mathematics teachers' interaction with resources (see Pepin et al. 2013). 


\section{Discussion and conclusion}

From our reading of the research that we have covered in this review and especially the articles included in this special issue of JMTE, we suggest that there is evidence, albeit still somewhat limited, to claim the following:

1. 'Task design' is by no means a trivial matter, and it needs particular consideration in terms of: what to design (e.g. individual tasks; groups of tasks; or task sequences-see Thanheiser et al.); which tools are necessary, or beneficial, for task design (e.g. manipulatives - see Hansen et al.; affordances and constraints of tools for selected topic areas, see Tempier; or cognitive tools, see Thanheiser et al.); and under what conditions (e.g. how to work with tensions between designers and practitioners, see Johnsen et al.; when does learning take place, see Jung and Brady).

2. Digital tools and task resources offer particular affordances that traditional resources cannot provide (e.g. collaborative work over the web-see Gueudet et al.), but there are also constrains that have to be considered, and immense care has to be taken to conduct such work for it to be successful (e.g. in terms of 'bootstrapping', or selection of participants_-see Hansen et al., particularities of tools, see Misfeldt and Zacho).

3. Not only do teachers benefit from being partners in task design (in terms of their professional learning), but it appears that without involving teachers in the processes, then selected aspects of task design would most likely be neglected (i.e. practicality for instruction and authenticity, see Wake et al.).

In terms of theoretical and methodological considerations, we lean on Pepin et al. (2013, p. 939) in arguing that 'existing theoretical and methodological frameworks capture only parts of the phenomena concerning teachers working in collectives with resources', and this is certainly true for work and interaction with mathematical tasks, including processes involving task design as a collective process. However, we contend that this special issue can add to knowledge, in the sense that the different research groups have used different approaches to 'partnership' and collective work with tasks (e.g. lesson study-see Wake et al.), and, more importantly, different theoretical frames for the analysis of their findings: design-based research (see Jung and Brady); cultural-historical activity theory (see Wake et al.; Gueudet et al.); didactical engineering (see Tempier); documentational/instrumentational approach to didactics (Gueudet et al.; Wake et al.); technological oedagogical content knowledge (Hansen et al.), to name but a few.

Watson and Ohtani (2015b, p. 13), in their overview of themes and issues emerging from the ICMI study on task design, point to a need for researchers to 'distinguish between theories of their observations and theories for designers and teachers and to consider drawing on teachers' and learners' situated perspectives when theorizing in either case'. They conclude by posing nine areas for further research, the ninth of these being 'the effectiveness of forms of collaboration and communication between task designers, classroom teachers, educators, and policymakers' (ibid, p. 14). This article reviews existing research on this topic, and this special issue of JMTE showcases current research that is tackling this issue. We hope that our review, and this special issue, provides a platform for further research on this important topic. 


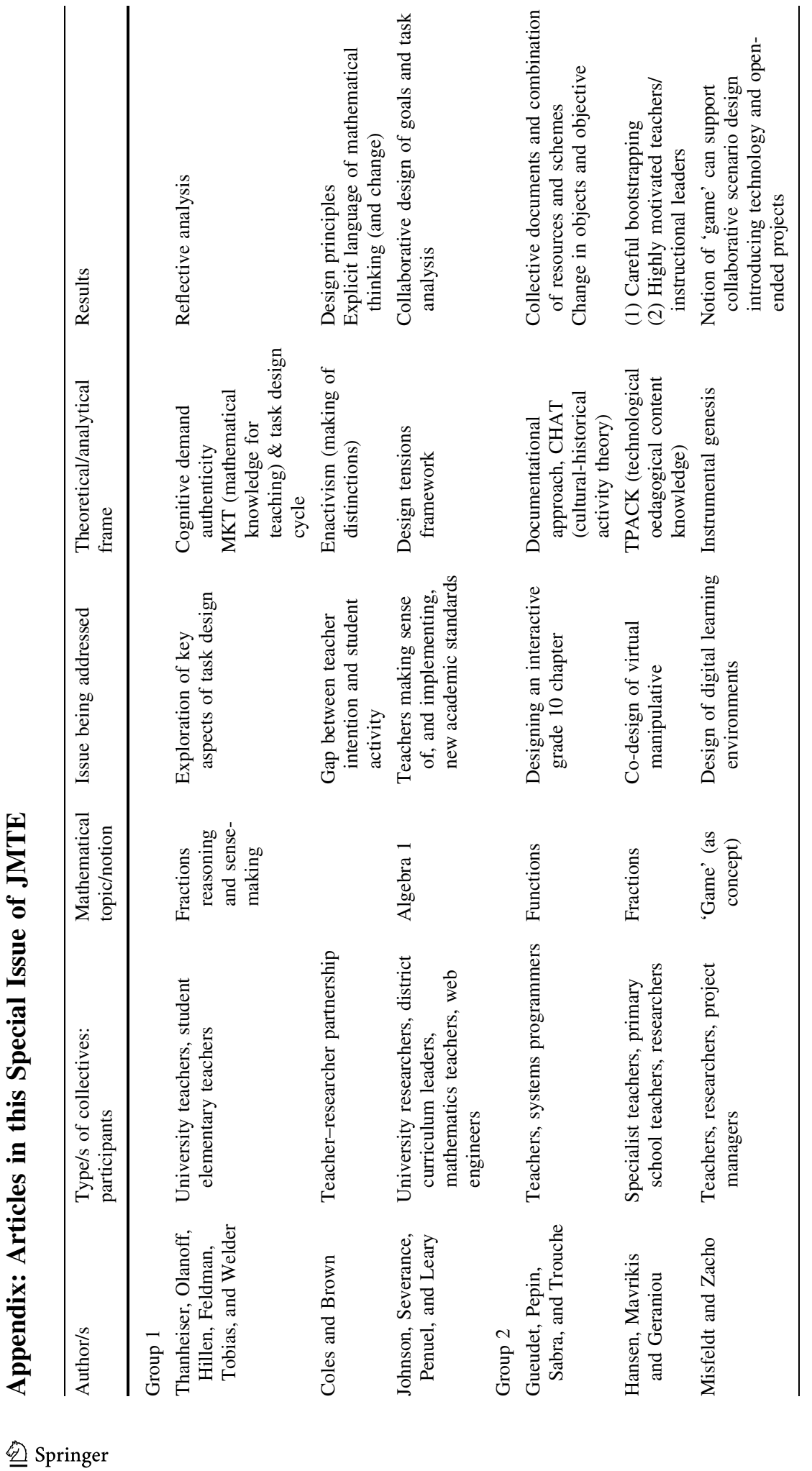




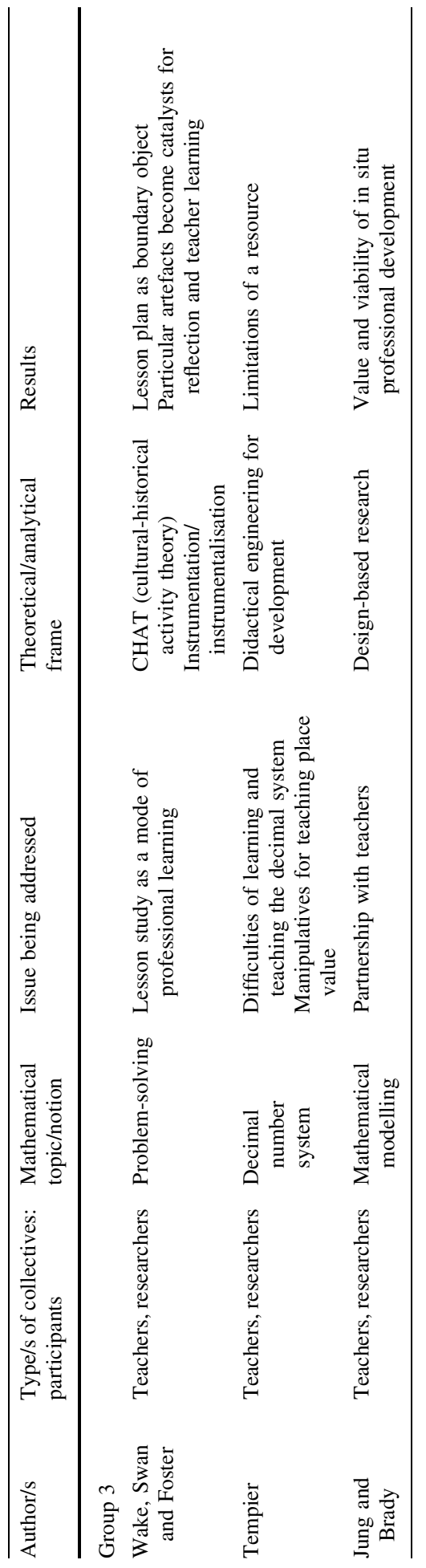




\section{References}

Arbaugh, F., \& Brown, C. A. (2005). Analyzing mathematical tasks: A catalyst for change? Journal of Mathematics Teacher Education, 8(6), 499-536.

Artigue, M. (1994). Didactical engineering as a framework for the conception of teaching products. In R. Biehler, R. W. Scholz, R. Strässer, \& B. Winkelmann (Eds.), Didactics of mathematics as a scientific discipline (pp. 27-39). Dordrecht, NL: Kluwer.

Askew, M., \& Canty, L. (2013). Teachers and researchers collaborating to develop teaching through problem solving in primary mathematics. In C. Margolinas (Ed.), Task design in mathematics education: Proceedings of ICMI Study 22 (pp. 531-540). Oxford, UK.

Ball, D. L., \& Cohen, D. (1996). Reform by the book: What is-Or might be-The role of curriculum materials in teacher learning and instructional reform? Educational Researcher, 25(9), 6-8.

Bannan-Ritland, B. (2008). Teacher design research: An emerging paradigm for teachers' professional development. In A. E. Kelly, R. A. Lesh, \& J. Baek (Eds.), Handbook of design research methods in education: Innovations in science, technology, mathematics and engineering (pp. 246-262). New York: Routledge.

Barbosa, J. C., \& de Oliveira, A. M. (2013). Conflicts in designing tasks at collaborative groups. In C. Margolinas (Ed.), Task design in mathematics education: Proceedings of ICMI Study 22 (pp. 541-548). Oxford, UK.

Bokhove, C., Jones, K., Mavrikis, M., Geraniou, E., \& Charlton, P. (2014). Co-designing electronic books: Boundary objects for social creativity. In K. Jones, et al. (Eds.), Proceedings of the international conference on mathematics textbook research and development 2014 (ICMT-2014) (pp. 167-172). Southampton: University of Southampton.

Brousseau, G. (1997). Theory of didactical situations in mathematics (edited and translated by N. Balacheff, M. Cooper, R. Sutherland, \& V. Warfield). Dordrecht, NL: Kluwer.

Brown, M. W. (2009). The teacher-tool relationship: Theorizing the design and use of curriculum materials. In J. T. Remillard, B. A. Herbel-Eisenmann, \& G. M. Lloyd (Eds.), Mathematics teachers at work: Connecting curriculum materials and classroom instruction (pp. 17-36). New York: Routledge.

Brown, M., \& Edelson, D. (2003). Teaching as design: Can we better understand the ways in which teachers use materials so we can better design materials to support their changes in practice. Evanston, IL: Center for Learning Technologies in Urban Schools.

Christiansen, B., \& Walther, G. (1986). Task and activity. In B. Christiansen, A. G. Howson, \& M. Otte (Eds.), Perspectives on mathematics education: Papers submitted by members of the Bacomet Group (pp. 243-307). Dordrecht, NL: D. Reidel.

Clarke, B., Grevholm, B., \& Millman, R. (2009). Tasks in primary mathematics teacher education. Berlin: Springer.

Cobb, P., \& Steffe, L. P. (1983). The constructivist researcher as teacher and model builder. Journal for Research in Mathematics Education, 14(2), 83-94.

Cobb, P., Zhao, Q., \& Dean, C. (2009). Conducting design experiments to support teachers' learning: A reflection from the field. Journal of the Learning Sciences, 18(2), 165-199.

Coburn, C. E., Penuel, W. R., \& Geil, K. E. (2013). Research-practice partnerships: A strategy for leveraging research for educational improvement in school districts. New York: William T. Grant Foundation.

Coles, A., \& Brown, L. (2015). Task design for ways of working: Making distinctions in teaching and learning mathematics. Journal of Mathematics Teacher Education. doi:10.1007/s10857-015-9337-4.

Davis, E. A., \& Krajcik, J. S. (2005). Designing educative curriculum materials to promote teacher learning. Educational Researcher, 34(3), 3-14.

de Araujo, Z., \& Singletary, L. M. (2011). Secondary mathematics teachers' conceptions of worthwhile tasks. In L. R. Wiest \& T. Lamberg (Eds.), Proceedings of the 33rd annual meeting of the North American chapter of the international group for the psychology of mathematics education (pp. 1207-1215). Reno, NV: University of Nevada, Reno.

Ding, L., Jones, K., \& Pepin, B. (2013). Task design in a school-based professional development programme. In C. Margolinas (Ed.), Task design in mathematics education: Proceedings of ICMI Study 22 (pp. 441-450). Oxford: University of Oxford.

Doyle, W. (1983). Academic work. Review of Educational Research, 53(2), 159-199.

Edwards, J.-A., \& Jones, K. (2003). Co-learning in the collaborative mathematics classroom. In A. PeterKoop, A. Begg, C. Breen, \& V. Santos-Wagner (Eds.), Collaboration in teacher education: Examples from the context of mathematics education (pp. 135-151). Dordrecht, NL: Kluwer. 
Engeström, Y. (1999). Activity theory and individual and social transformation. In Y. Engeström, R. Miettinen, \& R. L. Punamäki-Gitai (Eds.), Perspectives on activity theory (pp. 19-38). Cambridge: Cambridge University Press.

Engeström, Y. (2014). Learning by expanding: An activity-theoretical approach to developmental research (2nd ed.). Cambridge: Cambridge University Press.

Even, R., \& Olsher, S. (2014). Teachers as participants in textbook development: The integrated mathematics wiki-book project. In Y. Li \& G. Lappan (Eds.), Mathematics curriculum in school education (pp. 333-350). Berlin: Springer.

Fischer, G. (2001). Communities of interest: Learning through the interaction of multiple knowledge systems. In S. Bjornestad, R. Moe, A. Morch \& A. Opdahl (Eds.) Proceedings of the 24th IRIS Conference (pp. 1-14). Ulvik, Department of Information Science, Bergen, Norway, August 2001.

Fuglestad, A. B., Healy, L., Kynigos, C., \& Monaghan, J. (2010). Working with teachers: Context and culture. In C. Hoyles \& J.-B. Lagrange (Eds.), Mathematics education and technology: Rethinking the terrain (pp. 293-310). Berlin: Springer.

Geiger, V., Goos, M., Dole, S., Forgasz, H., \& Bennison, A. (2014). Devising principles of design for numeracy tasks. In In J. Anderson, M. Cavanagh, \& A. Prescott (Eds.), Curriculum in focus: Researchguided practice: Proceedings of the 37th annual conference of the Mathematics Education Research Group of Australasia (pp. 239-246). Sydney: MERGA.

Goodchild, S. (2014). Mathematics teaching development: Learning from developmental research in Norway. ZDM: International Journal on Mathematics Education, 46(2), 305-316.

Gravemeijer, K. (1993). The empty number line as an alternative means of representation for addition and subtraction. In J. de Lange, I. Huntley, C. Keitel, \& M. Niss (Eds.), Innovation in mathematics education by modeling and applications (pp. 141-159). Chichester: Ellis Horwood.

Gravemeijer, K. P. E., \& Cobb, P. (2006). Design research from a learning design perspective. In J. Akker, K. Gravemeijer, S. McKenney, \& N. Nieveen (Eds.), Educational design research (pp. 45-85). London: Taylor Francis.

Gueudet, G., Pepin, B., Sabra, H., \& Trouche, L. (2015). Collective design of an e-textbook: Teachers' collective documentation. Journal of Mathematics Teacher Education. doi:10.1007/s10857-015-9331-x.

Gueudet, G., Pepin, B., \& Trouche, L. (Eds.). (2012). From text to 'lived' resources: Mathematics curriculum materials and teacher development. Berlin: Springer.

Gueudet, G., Pepin, B., \& Trouche, L. (2013). Collective work with resources: An essential dimension for teacher documentation. ZDM: International Journal on Mathematics Education, 45(7), 1003-1016.

Gueudet, G., \& Trouche, L. (2009). Towards new documentation systems for mathematics teachers? Educational Studies in Mathematics, 71(3), 199-218.

Gueudet, G., \& Trouche, L. (2012a). Teachers' work with resources: Documentational geneses and professional geneses. In G. Gueudet, B. Pepin, \& L. Trouche (Eds.), From text to 'lived resources': Curriculum material and mathematics teacher development (pp. 23-41). Berlin: Springer.

Gueudet, G., \& Trouche, L. (2012b). Communities, documents and professional geneses: Interrelated stories. In G. Gueudet, B. Pepin, \& L. Trouche (Eds.), From text to 'lived' resources: Curriculum material and mathematics teacher development (pp. 23-41). Berlin: Springer.

Haggarty, L., \& Pepin, B. (2002). An investigation of mathematics textbooks and their use in English, French and German classrooms: Who gets an opportunity to learn what? British Educational Research Journal, 28(4), 567-590.

Hansen, A., Mavrikis, M., \& Geraniou, E. (2016). Supporting teachers' technological pedagogical content knowledge of fractions through co-designing a virtual manipulative. Journal of Mathematics Teacher Education. doi:10.1007/s10857-016-9344-0.

Henningsen, M., \& Stein, M. K. (1997). Mathematical tasks and student cognition: Classroom-based factors that support and inhibit high-level mathematical thinking and reasoning. Journal for Research in Mathematics Education, 28(5), 524-549.

Jaworski, B. (2001). Developing mathematics teaching: Teachers, teacher-educators and researchers as colearners. In F.-L. Lin \& T. J. Cooney (Eds.), Making sense of mathematics teacher education. Dordrecht, NL: Kluwer.

Jaworski, B. (2003). Research practice into/influencing mathematics teaching and learning development: Towards a theoretical framework based on co-learning partnerships. Educational Studies in Mathematics, 54(2-3), 249-282.

Jaworski, B. (2006). Theory and practice in mathematics teaching development: Critical inquiry as a mode of learning in teaching. Journal of Mathematics Teacher Education, 9(2), 187-211.

Jaworski, B., Goodchild, S., Eriksen, S., \& Daland, E. (2011). Mediating mathematics teaching development and pupils' mathematics learning: The life cycle of a task. In O. Zaslavsky \& P. Sullivan (Eds.), 
Constructing knowledge for teaching secondary mathematics: Tasks to enhance prospective and practicing teacher learning (pp. 143-160). Berlin: Springer.

Johnson, R., Severance, S., Penuel, W. R., \& Leary, H. (2015) Teachers, tasks, and tensions: Lessons from a research-practice partnership. Journal of Mathematics Teacher Education. doi:10.1007/s10857-0159338-3.

Jung, H., \& Brady, C. (2015). Roles of a teacher and researcher during in situ professional development around the implementation of mathematical modeling tasks. Journal of Mathematics Teacher Education. doi:10.1007/s10857-015-9335-6.

Knott, L., Olson, J., Adams, A., \& Ely, R. (2013). Task design: Supporting teachers to independently create rich tasks. In C. Margolinas (Ed.), Task design in mathematics education: Proceedings of ICMI Study 22 (pp. 599-608). Oxford, UK.

Krainer, K. (1993). Powerful tasks: A contribution to a high level of acting and reflecting in mathematics instruction. Educational Studies in Mathematics, 24(1), 65-93.

Lave, J., \& Wenger, E. (1991). Situated learning: Legitimate peripheral participation. Cambridge: Cambridge University Press.

Liljedahl, P. (2015). Numeracy task design: A case of changing mathematics teaching practice. ZDM: International Journal on Mathematics Education, 47(4), 625-637.

Maaß, K., Garcia, F. J., Mousoulides, N., \& Wake, G. (2013). Designing interdisciplinary tasks in an international design community. In C. Margolinas (Ed.), Task design in mathematics education: Proceedings of ICMI Study 22 (pp. 367-376). Oxford, UK.

Maher, C. A. (1987). The teacher as designer, implementer, and evaluator of children's mathematical learning environments. Journal of Mathematical Behavior, 6(3), 295-303.

Margolinas, C. (Ed.). (2014). Task design in mathematics education: Proceedings of ICMI Study 22. Oxford: University of Oxford.

Misfeldt, M., \& Zacho, L. (2015). Supporting primary-level mathematics teachers' collaboration in designing and using technology-based scenarios. Journal of Mathematics Teacher Education. doi:10. 1007/s10857-015-9336-5.

Moss, J., Hawes, Z., Naqvi, S., \& Caswell, B. (2015). Adapting Japanese Lesson Study to enhance the teaching and learning of geometry and spatial reasoning in early years classrooms: A case study. ZDM: International Journal on Mathematics Education, 47(3), 377-390.

Penuel, W. R., Fishman, B. J., Cheng, B. H., \& Sabelli, N. (2011). Organizing research and development at the intersection of learning, implementation, and design. Educational Researcher, 40(7), 331-337.

Pepin, B. (2015). Enhancing mathematics/STEM education: A 'resourceful' approach. Inaugural lecture, 27 November 2015, Technische Universiteit Eindhoven.

Pepin, B., Gueudet, G., \& Trouche, L. (2013). Re-sourcing teacher work and interaction: New perspectives on resource design, use and teacher collaboration. ZDM: The International Journal of Mathematics Education, 45(7), 929-943.

Prediger, S., Gravemeijer, K., \& Confrey, J. (2015). Design research with a focus on learning processes. ZDM: International Journal on Mathematics Education, 47(6), 877-891.

Remillard, J. T. (2005). Examining key concepts in research on teachers' use of mathematics curricula. Review of Educational Research, 75(2), 211-246.

Remillard, J., Herbel-Eisenmann, B. A., \& Lloyd, G. M. (Eds.). (2008). Mathematics teachers at work: Connecting curriculum materials and classroom instruction. New York: Routledge.

Ron, G., Zaslavsky, O. \& Zodik, I. (2013). Engaging teachers in the web of considerations underlying the design of tasks that foster the need for new mathematical concept tools. In C. Margolinas (Ed.), Task design in mathematics education: Proceedings of ICMI Study 22 (pp. 641-647). Oxford, UK.

Ruthven, K., \& Hennessy, S. (2002). A practitioner model of the use of computer-based tools and resources to support mathematics teaching and learning. Educational Studies in Mathematics, 49(1), 47-88.

Ruthven, K., \& Hofmann, R. (2013). Chance by design: Devising an introductory probability module for implementation at scale in English early-secondary education. ZDM: The International Journal of Mathematics Education, 45(3), 409-423.

Ruthven, K., Laborde, C., Leach, J., \& Tiberghien, A. (2009). Design tools in didactical research: Instrumenting the epistemological and cognitive aspects of the design of teaching sequences. Educational Researcher, 38(5), 329-342.

Schmidt, W. H., McKnight, C. C., Valverde, G. A., Houang, R. T., \& Wiley, D. E. (1997). Many visions, many aims: A cross-national investigation of curricular intentions in school mathematics. Dordrecht, NL: Kluwer.

Schoenfeld, A.H. (2009). Bridging the cultures of educational research and design. Educational Designer, $1(2), 1-23$ 
Sensevy, G. (2012). Patterns of didactic intentions, thought collective and documentation work. In G. Gueudet, B. Pepin, \& L. Trouche (Eds.), From text to 'lived' resources: Mathematics curriculum materials and teacher development (pp. 43-57). Berlin: Springer.

Sensevy, G., Forest, D., Quilio, S., \& Morales, G. (2013). Cooperative engineering as a specific designbased research. ZDM: International Journal on Mathematics Education, 45(7), 1031-1043.

Shimizu, Y., Kaur, B., Huang, R., \& Clarke, D. (2010). The role of mathematical tasks in different cultures. In Y. Shimizu, B. Kaur, R. Huang, \& D. Clarke (Eds.), Mathematical tasks in classrooms around the world (pp. 9-14). Rotterdam: Sense Publishers.

Stein, M. K., Grover, B. W., \& Henningsen, M. (1996). Building student capacity for mathematical thinking and reasoning: An analysis of mathematical tasks used in reform classrooms. American Educational Research Journal, 33(2), 455-488.

Stephan, M. L. (2015). Conducting classroom design research with teachers. ZDM: International Journal on Mathematics Education, 47(6), 905-917.

Sullivan, P., Clarke, D., \& Clarke, B. (2012). Teaching with tasks for effective mathematics learning. Berlin: Springer.

Sullivan, P., \& Mousley, J. (2001). Thinking teaching: Seeing mathematics teachers as active decision makers. In F.-L. Lin \& T. Cooney (Eds.), Making sense of mathematics teacher education (pp. 147-163). Dordrecht: Springer.

Swan, M. (2005). Improving learning in mathematics: Challenges and strategies. London: DfES.

Swan, M. (2011). Designing tasks that challenge values, beliefs and practices: A model for the professional development of practicing teachers. In O. Zaslavski \& P. Sullivan (Eds.), Constructing knowledge for teaching secondary mathematics: Tasks to enhance prospective and practicing teacher learning (pp. 57-71). Berlin: Springer.

Tempier, F. (2015). New perspectives for didactical engineering: An example for the development of a resource for teaching decimal number system. Journal of Mathematics Teacher Education. doi:10. 1007/s10857-015-9333-8.

Thanheiser, E., Olanoff, D., Hillen, A., Feldman, Z., Tobias, J. M., \& Welder, R. M. (2015). Reflective analysis as a tool for task redesign: The case of prospective elementary teachers solving and posing fraction comparison problems. Journal of Mathematics Teacher Education. doi:10.1007/s10857-0159334-7.

Tirosh, D., \& Wood, T. (Eds.). (2008). Tools and resources in mathematics teacher education. Rotterdam: Sense Publishers.

Törnroos, J. (2005). Mathematics textbooks, opportunity to learn and student achievement. Studies in Educational Evaluation, 31(4), 315-327.

Visnovska, J., Cobb, P., \& Dean, C. (2012). Mathematics teachers as instructional designers: What does it take? In G. Gueudet, B. Pepin, \& L. Trouche (Eds.), From text to 'lived' resources: Mathematics curriculum materials and teacher development (pp. 323-341). Berlin: Springer.

Wagner, J. (1997). The unavoidable intervention of educational research: A framework for reconsidering researcher-practitioner cooperation. Educational Researcher, 26(7), 13-22.

Wake, G., Swan, M., \& Foster, C. (2015). Professional learning through the collaborative design of problemsolving lessons. Journal of Mathematics Teacher Education. doi:10.1007/s10857-015-9332-9.

Watson, A., \& Mason, J. (2007). Taken-as-shared: A review of common assumptions about mathematical tasks in teacher education. Journal of Mathematics Teacher Education, 10(4-6), 205-215.

Watson, A. \& Ohtani, M. (2014). Task design in mathematics education: Discussion document. In C. Margolinas (Ed.), Task design in mathematics education: Proceedings of ICMI Study 22. Oxford: University of Oxford.

Watson, A., \& Ohtani, M. (Eds.). (2015a). Task design in mathematics education: An ICMI study. Berlin: Springer.

Watson, A., \& Ohtani, M. (2015b). Themes and issues in mathematics education concerning task design. In A. Watson \& M. Ohtani (Eds.), Task design in mathematics education: An ICMI study (pp. 3-15). Berlin: Springer.

Wenger, E. (1998). Communities of practice: Learning, meaning, and identity. Cambridge: Cambridge University Press.

Wittmann, E. C. (1995). Mathematics education as a 'design science'. Educational studies in Mathematics, 29(4), 355-374.

Wittmann, E. C. (2001). Developing mathematics education in a systemic process. Educational Studies in Mathematics, 48(1), 1-20.

Yang, X. (2014). Conception and characteristics of expert mathematics teachers in China. Berlin: Springer.

Zaslavsky, O., \& Sullivan, P. (Eds.). (2011). Constructing knowledge for teaching secondary mathematics: Tasks to enhance prospective and practicing teacher learning. Berlin: Springer. 